\title{
Inhibition of carbonic anhydrase isozymes with benzene sulfonamides incorporating thio, sulfinyl and sulfonyl glycoside moieties
}

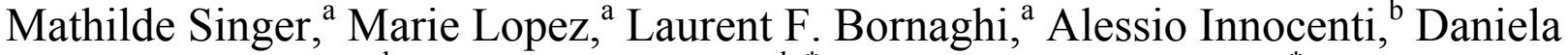 \\ Vullo, ${ }^{\mathrm{b}}$ Claudiu T. Supuran ${ }^{\mathrm{b}, *}$ and Sally-Ann Poulsen ${ }^{\mathrm{a}, *}$ \\ ${ }^{\mathrm{a}}$ Eskitis Institute for Cell and Molecular Therapies, Griffith University, 170 Kessels Road, Nathan, Queensland 4111, \\ Australia, and Polo Scientifico, Laboratorio di Chimica Bioinorganica, Rm. 188, Università degli Studi di Firenze, \\ Via della Lastruccia 3, 50019 Sesto Fiorentino, Florence, Italy
}

This is where the receipt/accepted dates will go; Received Month XX, 2000; Accepted Month XX, 2000 [BMCL RECEIPT]

\begin{abstract}
A series of benzene sulfonamides incorporating thio, sulfinyl or sulfonyl glycoside moieties were synthesized. These glycoconjugates were investigated for their ability to inhibit the enzymatic activity of four human carbonic anhydrases (hCA): isozymes I, II and tumour-associated isozymes IX and XII. The oxidation state of the sulfur in the carbohydrate tail moiety did not influence either enzyme inhibition potency or isozyme selectivity even though presenting opportunities for differing interactions with the target isozymes.
\end{abstract}

Carbonic anhydrases (CA, EC 4.2.1.1) are ubiquitous zinc metalloenzymes spread across the phylogenetic tree. ${ }^{1}$ There are 16 different CA isozymes presently known in mammals. These enzymes catalyze a simple, yet critical, reaction: the reversible hydration of carbon dioxide to bicarbonate anion and a proton i.e. $\mathrm{CO}_{2}+$ $\mathrm{H}_{2} \mathrm{O} \leftrightarrow \mathrm{HCO}_{3}^{-}+\mathrm{H}^{+}$. Hydration does not proceed appreciably under physiological conditions in the absence of CA. The $\mathrm{Zn}^{2+}$ core of CA serves an essential function: it is a strong Lewis acid that binds to and activates the hydrating water molecule. CA facilitates deprotonation of water to generate the strongly basic hydroxide anion $\left(\mathrm{OH}^{-}\right)$under physiological conditions. Hydroxide anion is the reactive species in the hydration of $\mathrm{CO}_{2}$ leading to formation and release of $\mathrm{HCO}_{3}{ }^{-}$. The components of this reaction are known to regulate a broad range of physiological functions and clinical modulation of CA activity by inhibitors has proven a reliable treatment for a range of human disease states. ${ }^{1}$
There are two known cancer-associated CA isozymes for which elevated gene expression levels are found in a broad spectrum of solid hypoxic tumour types, these are isozymes IX and XII. ${ }^{2-6}$ Aromatic sulfonamide compounds are the classical CA inhibitors and compounds with this structural motif have been shown to reverse or suppress the effects mediated by the cancer-associated CAs: namely tumour acidification, cancer cell growth and tumour invasion. ${ }^{1-6}$ Isozymes CA IX and XII also share a spatial localization that distinguishes them from the physiologically dominant CA I and II. CA IX and XII are transmembrane proteins that orient their CA catalytic domain extracellularly, while isozymes I and II are soluble proteins located within the cytosol. The development of CA inhibitors with an impaired ability to diffuse through lipid membranes is one possible and attractive means by which to selectively target cancer associated CA isozymes. ${ }^{7}$ Recently our group has demonstrated that by "click-tailing" sugar moieties to the classic high-

*Corresponding Authors. E-mail addresses: s.poulsen@griffith.edu.au (S.-A. Poulsen); claudiu.supuran@unifi.it (C.T. Supuran). 
affinity aromatic sulfonamide pharmacophore $\left(\mathrm{ArSO}_{2} \mathrm{NH}_{2}\right)$ - we were able to deliver glycoconjugate sulfonamide inhibitors that were potent and selective towards the CA isozyme IX in vitro. ${ }^{8-11} \mathrm{We}$ have reported the synthesis and $\mathrm{CA}$ inhibition properties for a series of benzene sulfonamides containing triazole- $O$ glycoside tails. ${ }^{9}$ The replacement of the naturally occurring $O$-glycosidic linkages by $S$-glycosides is an approach practiced in the synthesis of carbohydrate containing compounds as an avenue to enhance the stability of the glycosidic linkage towards enzymatic hydrolysis whilst retaining vital molecular recognition interactions with biological targets. ${ }^{12-15}$ There is an increasing awareness of the biological importance of thioglycosides owing to these favourable attributes and several are in clinical use. ${ }^{12-15}$ Herein we explore further our very effective "click-tailing" strategy to synthesize a new class of glycoconjugate sulfonamides through appending $S$-propynyl glycosides of three different oxidation states onto the 4-azido benzenesulfonamide scaffold. This library was inspired by the therapeutic drugs brinzolamide (BRZ) and dorzolamide (DRZ), used clinically as topically acting CA inhibitors for the treatment of glaucoma. The sulfone moiety of BRZ and DRZ proved critical to the effective therapeutic properties of these CA inhibitors - assisting with water solubility yet retaining sufficient lipophilicity to penetrate the cornea.

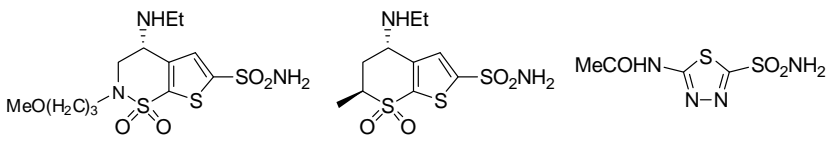

$$
\begin{aligned}
& \text { brinzolamide dorzolamide acetazolamide }
\end{aligned}
$$

A panel of acetylated $S$-propynyl, sulfinyl propynyl and sulfonyl glycosides (1-6) were synthesized from commercially available per- $O$-acetylated sugars - Dglucose $(\rightarrow$ 1-3) and D-galactose $(\rightarrow$ 4-6), Scheme 1 . The per- $O$-acetylated $\beta$-S-propynyl glycosides 1 and $\mathbf{4}$ were generated by Lewis acid catalyzed $\left(\mathrm{BF}_{3} \cdot \mathrm{Et}_{2} \mathrm{O}\right)$ glycosylation of the $\beta$-acetate precursors with thiourea to generate the $S$-glycosyl isothiourea intermediates which were subsequently transformed into the $S$ propynyl glycosides by treatment with $\mathrm{Et}_{3} \mathrm{~N}$ and propargyl bromide. ${ }^{16}$ Oxidation of $\mathbf{1}$ and $\mathbf{4}$ with excess $m$ CPBA in $\mathrm{CH}_{2} \mathrm{Cl}_{2}$ gave per- $O$-acetylated $\beta$-sulfonyl propynyl glycosides $\mathbf{3}$ and $\mathbf{6}$. Oxidation was generally complete following $3.5 \mathrm{~h}$ of stirring at ambient temperature as evidenced by TLC. The per- $O$-acetylated $\beta$-sulfinyl propynyl glycosides $\mathbf{2}$ and $\mathbf{5}$ were prepared as a mixture of diastereomers $(1: 1)$ by mono-oxidation of 1 and 4 with 1.0 equiv. $m \mathrm{CPBA}$ in $\mathrm{CH}_{2} \mathrm{Cl}_{2}$ at $0{ }^{\circ} \mathrm{C}$ for 0.5 h. A number of eluents were tested to separate the diastereomers by chromatography including EtOAc/hexane, acetone/toluene and $\mathrm{MeOH} / \mathrm{CH}_{2} \mathrm{Cl}_{2}$ albeit without success. Although recrystallization of the diastereomeric mixtures from $\mathrm{MeOH}$ could allow enrichment in one of the diastereomers $(3: 1)$, we elected to utilize compounds $\mathbf{2}$ and $\mathbf{5}$ as $1: 1$ diastereomeric mixtures in the subsequent synthesis of glycoconjugates. No over oxidation to the sulfone was observed using the conditions described.

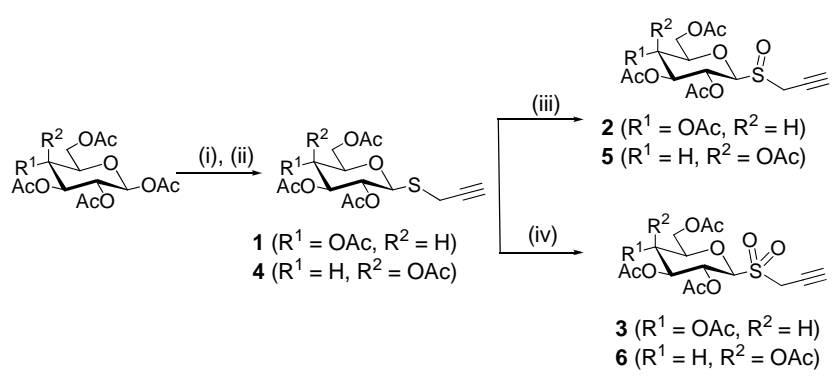

Scheme 1. ${ }^{\mathrm{a}}$ Reagents and conditions: (i) thiourea, $\mathrm{BF}_{3} \cdot \mathrm{Et}_{2} \mathrm{O}, \mathrm{CH}_{3} \mathrm{CN}$, reflux, $0.5 \mathrm{~h}$; (ii) $\mathrm{Et}_{3} \mathrm{~N}$, propargyl bromide, rt, overnight, 55-59\%; (iii) 1 equiv. $m \mathrm{CPBA}, \mathrm{CH}_{2} \mathrm{Cl}_{2}, 0{ }^{\circ} \mathrm{C}, 0.5 \mathrm{~h}, 70-73 \%$; (iv) excess $m \mathrm{CPBA}$, $\mathrm{CH}_{2} \mathrm{Cl}_{2}, \mathrm{rt}, 3.5 \mathrm{~h}, 93-95 \%$. ${ }^{\mathrm{b}} \mathrm{Compounds} \mathbf{2}$ and $\mathbf{5}$ are racemic at sulfur.

Next the library of 12 benzenesulfonamides (compounds 8-19) containing triazole-tethered glycoside tails was constituted by $\mathrm{Cu}(\mathrm{I})$-catalyzed $1,3-$ dipolar cycloaddition. ${ }^{17,18}$ of the azido scaffold 7 with our panel of per- $O$-acetylated thiosugar-connected propynyl derivatives (1-6), Scheme 2. Compound 7 was synthesized from commercially available sulfanilamide by diazo transfer under neutral conditions as described previously. ${ }^{9,19}$ Consistent with our earlier findings the triazole forming reaction proceeded smoothly when using a catalyst loading of $10 \mathrm{~mol} \%$ of the $\mathrm{Cu}(\mathrm{I})$ source and $20 \mathrm{~mol} \%$ of sodium ascorbate. ${ }^{8-11}$ Reactions were complete (as evidenced by TLC) after $2 \mathrm{~h}$ vigorous stirring. De- $O$-acetylation of 8-13 by methanolic sodium methoxide was employed to liberate the corresponding fully deprotected sugar analogues 14-19, Scheme 2.

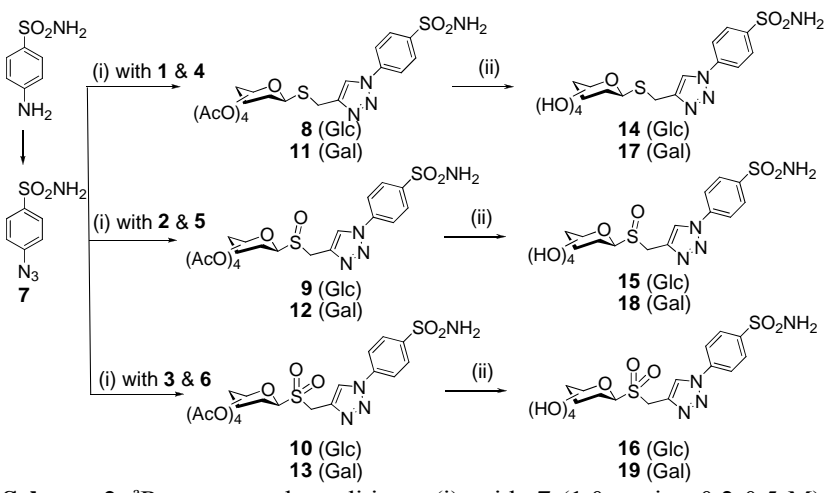

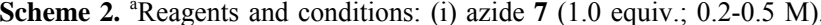
glycoside 1-6 (1.0 equiv.), $\mathrm{CuSO}_{4} .5 \mathrm{H}_{2} \mathrm{O}$ (0.1 equiv.), sodium ascorbate (0.2 equiv.), 8:2 EtOH: $\mathrm{H}_{2} \mathrm{O}, 40{ }^{\circ} \mathrm{C}, 2 \mathrm{~h}, 45-83 \%$; (ii) $1.0 \mathrm{M} \mathrm{NaOCH}_{3}$, $\mathrm{CH}_{3} \mathrm{OH}$, rt, overnight, 63-100\%. ${ }^{b}$ Compounds 9, 12, 15 and 18 are equimolar mixtures of $S$-epimers.

Enzyme inhibition data for the new glycoconjugate sulfonamides 8-19 were determined by assaying the CA catalyzed hydration of $\mathrm{CO}_{2}$, Table $1 .{ }^{20}$ Reference data for clinically used CA inhibitors acetazolamide (AZA), brinzolamide (BRZ) and dorzolamide (DRZ) have also been included for comparison with the compounds reported in this study. Data for $O$-glucoside and $O$ - 
galactoside analogues $\mathbf{2 0 - 2 3}$, reported recently by our groups, are included for discussion purposes. ${ }^{9}$

Table 1. Inhibition and selectivity ratio data for $\mathbf{1}$, new glycoconjugate sulfonamides 8-19, $O$-glycoside analogues 20-23 and standard inhibitors against human isozymes hCA I, II, IX and XII.

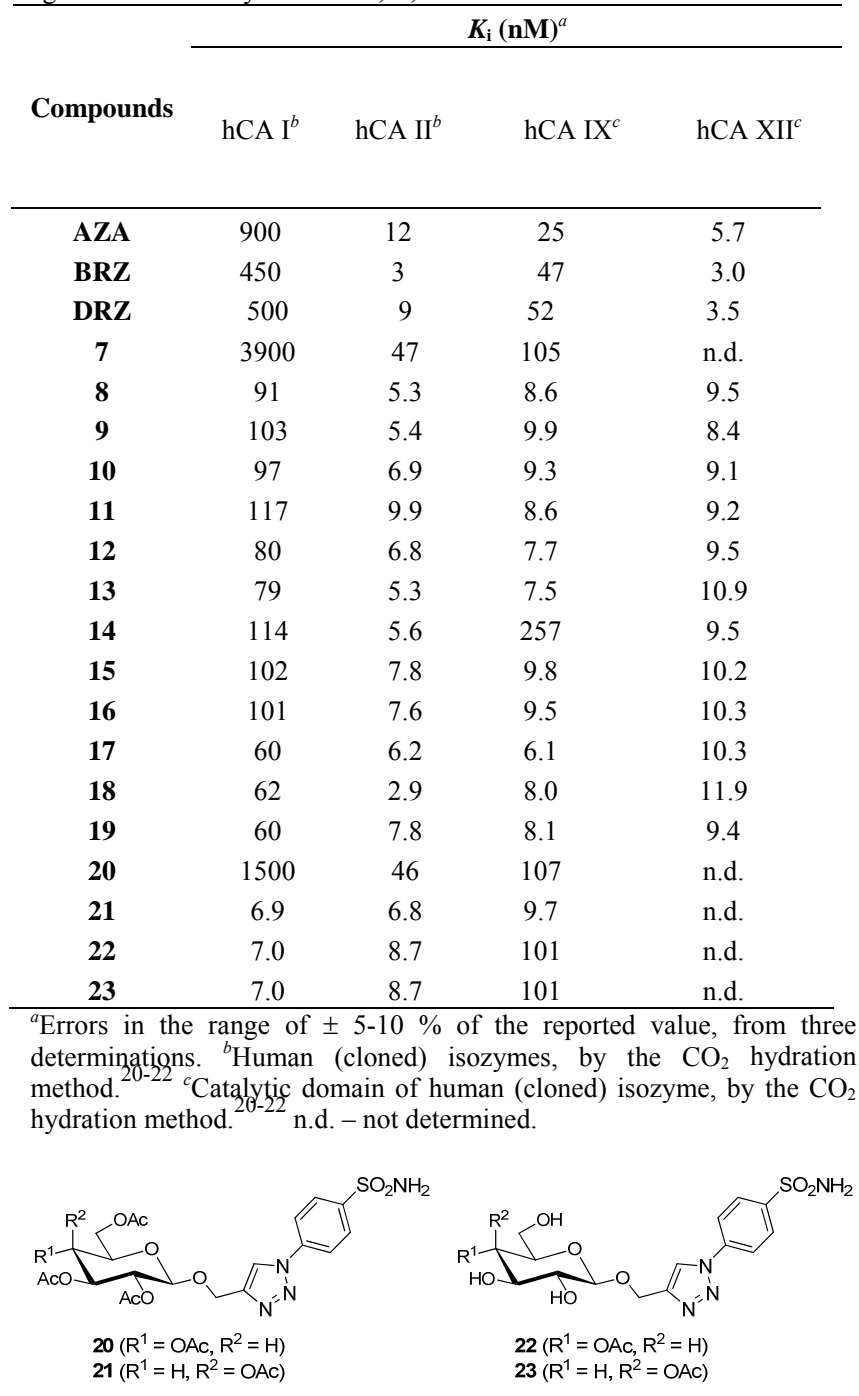

The parent azido scaffold $\mathbf{7}$ had greatest efficacy against hCA II $\left(K_{\mathrm{i}}\right.$ of $\left.47 \mathrm{nM}\right)$, approximately 2 -fold weaker inhibition against the tumour-associated hCA IX (105 $\mathrm{nM})$ and 80-fold weaker inhibition against hCA I (3900 $\mathrm{nM})$. The inhibition profile for 7 was weaker at all isozymes compared to the clinically used sulfonamide inhibitors AZA, BRZ and DRZ, however 7 did have a similar selectivity profile to AZA. The new glycoconjugates were investigated both in the per- $O$ acetylated form (compounds 8-13) and the free hydroxyl form (compounds 14-19). All glycoconjugates were stronger inhibitors than the parent azido compound 7 at the CA isozymes tested.

Glycosides were potent inhibitors of hCA II $\left(\mathrm{K}_{\mathrm{i}} \mathrm{s}\right.$ 2.9-9.9 $\mathrm{nM})$, IX $\left(\mathrm{K}_{\mathrm{i}} \mathrm{s}\right.$ 6.1-9.9 $\left.\mathrm{nM}\right)$ and XII $\left(\mathrm{K}_{\mathrm{i}} \mathrm{s}\right.$ 8.4-11.9 $\left.\mathrm{nM}\right)$ with $\mathrm{K}_{\mathrm{i}}$ values narrowly distributed - and just one outlier to this trend - compound $\mathbf{1 4}$ with a $\mathrm{K}_{\mathrm{i}}$ of $257 \mathrm{nM}$ at hCA IX. The tight distribution of $\mathrm{K}_{\mathrm{i}}$ values surprised us as we had expected that the oxidation of the sulfur would provide an increased opportunity for these small molecule inhibitors to interact through hydrogen bonding to amino acids within the various $\mathrm{CA}$ active sites and that this would be observed indirectly by modulating $\mathrm{K}_{\mathrm{i}}$ values. In fact, the oxidation state of the sulfur had virtually no impact on the CA inhibition constants determined. At hCA I inhibition by 8-19 was typically weaker (10-20 -fold) than for all other isozymes with $\mathrm{K}_{\mathrm{i}} \mathrm{s}$ in the mid-high $\mathrm{nM}$ range (60-117 $\mathrm{nM})$. The oxidation state of the sulfur also did not effect $\mathrm{CA}$ I enzyme inhibition, while galactose-OH compounds (17-19, $\mathrm{K}_{\mathrm{i}} \mathrm{s}$ 60-62 $\mathrm{nM}$ ) were marginally stronger inhibitors than glucose-OH compounds (14-16, $\mathrm{K}_{\mathrm{i}} \mathrm{S}$ 101-114 nM) at hCA I. Comparison of CA inhibition of our recently reported $O$-glycosides 20-23 demonstrates that the replacement of $O$ by $S$ (compounds 8, 11, 14, 17), SO (compounds 9, 12, 15, 18) and $\mathrm{SO}_{2}$ (compounds $\left.10,13,16,19\right)$ typically gives weaker inhibitors at hCA I, while at CA II inhibition is similar, and at CA IX inhibition is generally stronger. This trend indicates that the sulfur analogues may prove superior for selectively targeting tumour associated hCA IX.

To deliver CA based cancer therapies or diagnostics will benefit enormously from the development of inhibitors that target the tumour-associated CA isozymes. Selective inhibition among CA isozymes is however challenging owing to conservation of active site topology within this enzyme class. Using our "click-tailing" strategy we have appended thio, sulfinyl and sulfonyl glycoside tail moieties onto the benzenesulfonamide CA pharmacophore. This work presents a new class of glycoconjugate CA inhibitors comprising $S$-linked glycosides in three oxidation states. The anticipated stability of these glycoside CA inhibitors towards endogenous glycosidases combined with the effective enzyme inhibition properties demonstrated in this study towards CA IX and XII may render these carbohydrate-based sulfonamides as valuable candidates for future targeting of CAs for therapeutic applications in hypoxic tumours. Current research in our laboratory is targeted towards identifying the structural features within the CA active site that explain the tight distribution of inhibition constants observed for this new class of inhibitors so as to support future rationale design approach for the synthesis of CA inhibitors. The minimal impact of the oxidation state at the sulfur atom on CA enzyme inhibition may appear a profitable finding in future CA drug development strategies where it is necessary to modify physicochemical properties of inhibitors without impacting on drug-enzyme molecular recognition interactions. This study is therefore a valuable step in the ongoing research to improve the characteristics of CA inhibitors. 
Acknowledgment: This work was financed in part by the Australian Research Council (Grant number DP0877554 to S.-A.P.); the Eskitis Institute for Cell and Molecular Therapies and an EU grant of the $6^{\text {th }}$ framework programme (DeZnIT project to C.T.S.). We thank Hoan The $\mathrm{Vu}$ for undertaking accurate mass measurements.

Supplementary Material Available: Synthetic procedures, compound characterization data and ${ }^{1} \mathrm{H}$ NMR spectra for new compounds.

\section{References}

1. Supuran, C.T. Nat. Rev. Drug Disc. 2008, 7, 168.

2. Thiry, A.; Dogné, J.M.; Masereel, B.; Supuran, C.T. TIPS 2006, 27, 566.

3. Svastova, E.; Hulikova, A.; Rafajova, M.; Zatovicova, M.; Gibadulinova, A.; Casini, A.; Cecchi, A.; Scozzafava, A.; Supuran, C.T.; Pastorek, J.; Pastorekova, S. FEBS Lett. 2004, 577, 439.

4. Wykoff, C.C.; Beasley, N.J.; Watson, P.H.; Turner, K.J.; Pastorek, J.; Sibtain, A.; Wilson, G.D.; Turley, H.; Talks, K.L.; Maxwell, P.H.; Pugh, C.W.; Ratcliff, P.J.; Harris, A.L. Cancer Res. 2000, 60, 7075.

5. Semenza, G.L. Cancer Metastasis Rev. 2007, 26, 223.

6. Winum, J.-Y.; Rami, M.; Scozzafava, A.; Montero, J.L.; Supuran, C.T. Med Res Rev. 2008, 28, 445.

7. Winum, J.-Y.; Poulsen S.-A.; Supuran C.T. Med. Res. Rev. 2009, Published Online: Dec 3 2008, DOI: 10.1002/med.20141.

8. Wilkinson B.L.; Innocenti A.; Vullo D.; Supuran C.T.;
Poulsen S.-A. J. Med. Chem. 2008, 51, 1945.

9. Wilkinson B.L.; Bornaghi L.F.; Houston T.A.; Innocenti A.; Vullo D.; Supuran C.T.; Poulsen S.-A. J. Med. Chem. 2007, 50, 1651.

10. Wilkinson B.L.; Bornaghi L.F.; Houston T.A.; Innocenti A.; Vullo D.; Supuran C.T.; Poulsen S.-A. Bioorg. Med. Chem. Lett. 2007, 17, 987.

11. Wilkinson B.L.; Bornaghi L.F.; Houston T.A.; Innocenti A.; Supuran C.T.; Poulsen S.-A. J. Med. Chem. 2006, 49, 6539 .

12. Driguez, H. Top. Curr. Chem. 1997, 187, 85.

13. Witczak, Z.J. Curr. Med. Chem. 1999, 6, 165.

14. Pachamuthu, K.; Schmidt, R.R. Chem. Rev. 2006, 106, 160.

15. Driguez, H. ChemBioChem 2001, 2, 311.

16. Ibatullin, F.M.; Shabalin, K.A.; Jänis; J.V.; Shavvac, A.G. Tetrahedron Lett. 2003, 44, 7961.

17. Rostovtsev, V. V.; Green, L. G.; Fokin, V. V.; Sharpless, K. B. Angew. Chem. Int. Ed. 2002, 41, 2596.

18. Tornøe, C. W.; Christensen, C.; Meldal, M. J. Org. Chem. 2002, 67, 3057.

19. Das, J.; Patil, S.N.; Awasthi, R.; Narasimhulu, C.P.; Trehan, S. Synthesis 2005, 11, 1801.

20. Khalifah, R.G. J. Biol. Chem. 1971, 246, 2561.

21. Vullo, D.; Innocenti, A.; Nishimori, I.; Pastorek, J.; Scozzafava, A.; Pastoreková, S.; Supuran, C.T. Bioorg. Med. Chem. Lett. 2005, 15, 963.

22. Winum, J.-Y.; Vullo, D.; Casini, A.; Montero, J.-L.; Scozzafava, A.; Supuran, C.T. J. Med. Chem. 2003, 46, 5471. 